\title{
Personality and anxiety disorders: examination of revised reinforcement sensitivity theory in clinical generalized anxiety disorder, social anxiety disorder, and panic disorder
}

\author{
Behrooz Afshari \\ Department of Clinical Psychology, Kashan University of Medical Science, Kashan, Iran
}

\section{BACKGROUND}

Personality has been implicated in the development and continuation of mental disorders. One major advance in the personality field came with the reinforcement sensitivity theory (RST). The study of personality can help explicate the pathology of anxiety disorders. To this end the present study compared the profile of the revised reinforcement sensitivity theory ( $r$-RST) of personality in generalized anxiety disorder (GAD), social anxiety disorder (SAD), and panic disorder (PD).

\section{PARTICIPANTS AND PROCEDURE}

Seventy-eight GAD patients, 76 SAD patients, 72 PD patients, and 85 healthy individuals participated in the present study. All participants were assessed with the Structured Clinical Interview for DSM-IV Axis I disorders (SCID-I), Beck Depression Inventory, Jackson-5 Questionnaire, Generalized Anxiety Disorder Questionnaire, Panic and Agoraphobia Scale, and Social Phobia Inventory. Ethical approval for this study was obtained from the Research Deputy of
Kashan University of Medical Sciences. Participants were given information about the study and provided informed consent in writing.

\section{RESULTS}

Data were analyzed by chi-square, independent $t$-test, analysis of variance, and multivariate analysis of variance. All patients were higher on Flight than the control group. Also, all patients and healthy controls differed in the revised reinforcement sensitivity theory.

CONCLUSIONS

The more nuanced knowledge from the revised reinforcement sensitivity theory may be helpful in the diagnosis, etiology, and psychotherapy of anxiety disorders.

\section{KEY WORDS}

revised reinforcement sensitivity theory; behavioral brain systems; generalized anxiety disorder; social anxiety disorder; panic disorder

Corresponding Author - Behrooz Afshari, Department of Clinical Psychology, Kashan University of Medical Science, Ghotb Ravandi Str., 8715973474 Kashan, Iran, e-mail: behrooz.afshari71@gmail.com AUthors' CONTRIBUtion - A: Study design - B: Data collection - C: Statistical analysis - D: Data interpretation .

E: Manuscript preparation · F: Literature search · G: Funds collection

TO CITE THIS ARTICLE - Afshari, B. (2020). Personality and anxiety disorders: examination of revised reinforcement sensitivity theory in clinical generalized anxiety disorder, social anxiety disorder, and panic disorder. Current Issues in Personality Psychology, 8(1), 52-60. 


\section{BACKGROUND}

Personality has been implicated in the development and continuation of mental disorders. Recent studies have assessed the relevance of various biological theories of personality for generalized anxiety disorder (GAD), social anxiety disorder (SAD), and panic disorder (PD) (Claridge \& Davis, 2013). For example, according to Eysenck's arousal theory, introverts are prone to suffer from anxiety because they more easily develop classically emotional responses; this made the introverted neurotic prone to anxiety disorders (Corr, 2008). Neuroticism has been associated with negative emotions, such as anxiety, depression and anger. Also, Cloninger's personality theory has been used widely to explain anxiety disorders; people who are highly persistent (e.g. ambitious and perfectionistic) are more likely to have anxiety disorders; and those high in Persistence tend to experience increases in both positive and negative emotions (Cloninger, Zohar, Hirschmann, \& Dahan, 2012).

\section{REINFORCEMENT SENSITIVITY THEORY}

One major advance in the personality field came with the reinforcement sensitivity theory (RST), a biobehavioral theory of personality (Gray, 1981, 1982). In RST, the Fight and Flight System (FFS) was conceived of as a defensive mechanism, sensitive to unconditioned punishment and unconditioned aversive stimuli (Gray, 1987). For the biological underpinnings of RST, see McNaughton and Corr, 2008. The original version of RST assumes that individual differences reflect the differential sensitivity of the Behavioral Activation System (BAS) and the Behavioral Inhibition System (BIS). People who have a high BAS are reward-sensitive, are more likely to engage in highrisk behaviors, and they are more impulsive. The BAS system is responsible for positive emotions; and excessive sensitivity of this system leads to behaviors that are likely to lead to a reward, but at the expense of failing to pay due regard to the possibility of negative consequences. People with high BIS are more likely to be inhibited; activity of this system leads to anxiety and rumination, and makes the person more generally aware of signs of danger (Gray, 1982).

\section{REVISED REINFORCEMENT SENSITIVITY THEORY}

The original version of RST was revised by Gray and McNaughton (2000). According to this revised (r-RST) approach: (1) r-BAS is responsible for responding to potentially rewarding stimuli, conditioned or unconditioned; (2) the expanded Fight-Flight-Freeze system (FFFS) mediates responses to punishing stimuli, conditioned or non-conditioned; and (3) the r-BIS is responsible for solving the target conflict of all kinds but particularly ones entailing the BAS and FFFS. Goal conflict is resolved by activation of the FFFS to avoid the threat, or a return to normal BAS functioning - however, especially in clinical conditions, the BIS can be continuously activated and conflict may not be resolved, leading to clinical symptoms.

The BIS high reactivity indicates the extent of vulnerability to anxiety disorders (Gray \& McNaughton, 2000). The BIS can also be a predictor of SAD (Cremers \& Roelofs, 2016). The BIS inhibits targetbased behaviors to respond to aversive stimuli and is associated with feelings of anxiety, hopelessness, and sadness that are common in anxiety disorders (Neal \& Gable, 2017). Studies have also shown that BIS is associated with punishment, anxiety, fear, and avoidance behaviors. The r-BIS is associated with social anxiety, panic, fear, and stress (Harnett, Loxton, \& Jackson, 2013).

\section{STUDY OF PERSONALITY IN ANXIETY DISORDERS}

The BIS generates anxiety, which includes the inhibition of conflicting behaviors, and the engagement of risk assessment processes. High levels of BIS lead to risk of aversion like GAD that increases under conditions of conflict and create pain or the threat of death (Corr, 2008).

$\mathrm{SAD}$ is characterized by a persistent fear of one or more social situations with exposure to unfamiliar people or to possible scrutiny by others (APA, 2013). A person with SAD fears that he or she will act in a way that will be embarrassing, and exposure to the feared situations almost invariably provokes anxiety (Stein \& Stein, 2008). Also, SAD has a positive relationship with neuroticism and a negative relationship with extraversion (Bienvenu, Hettema, Neale, Prescott, \& Kendler, 2007; Kotov, Watson, Robles, \& Schmidt, 2007). Behavioral inhibition is one of the early indicators of social anxiety (Cremers \& Roelofs, 2016). Also, Harm Avoidance and Self-Directedness are closely associated with social anxiety symptoms. Greater variations in certain dimensions of the temperament and character, such as Harm Avoidance and Self-Directedness, indicate vulnerability and prediction of the development of SAD (Solmaz et al., 2018).

According to Eysenck's theory, neurotic people experience negative affect (fight-or-flight) (Corr, 2008). Regarding anxiety, Gray and McNaughton (2000) proposed that individual differences in reactivity of the BIS not only underlie the normal personality dimension of trait anxiety/neuroticism but also underlie vulnerability to the anxiety disorders (Gray \& McNaughton, 2000). 
Symptoms of depression overlap with anxiety disorders such as rumination, seen in both disorders (Nolen-Hoeksema, 2000). SAD is strongly associated with depression (Stein \& Chavira, 1998), and patients with SAD are more likely to experience depression later (Ohayon \& Schatzberg, 2010). Among anxiety disorders, PD is also highly associated with depression. Symptoms of depression in PD make a person's condition much worse (Lesser et al., 1988). GAD and depression also overlap with each other so that GAD is less independent of depression and that most patients develop depression eventually. Understanding the comorbidity of depression and anxiety disorders is important because treatment of the first disorder can prevent the occurrence of the second disorder (Moffitt et al., 2007). The overlap of depression and anxiety disorders may increase the risk of future psychiatric disorders (Kessler et al., 2008).

Each of the anxiety disorders, SAD, GAD and PD, is associated with certain personality traits. SAD has been positively correlated with perfectionism and neuroticism (Flett, Hewitt, \& Dyck, 1989; Kashdan, 2002). GAD has been positively correlated with harm avoidance (a behavioral pattern of avoiding punishing stimuli) and neuroticism (Sharma, 2003; Starcevic, Uhlenhuth, Fallon, \& Pathak, 1996). PD has been correlated with neuroticism and introversion (Carrera et al., 2006). In this study, we examined personality differences between GAD, SAD and PD. Also, in examining Jackson-5 subscales, effect size in r-BAS was higher than in other subscales and for Flight was lower than for the others.

\section{STUDY AIMS}

The literature to date has largely focused on the original RST; in contrast, very little research has employed r-RST. The aim of the present study is to address this issue by examining the behavioral systems of r-RST, i.e., fight, flight, freeze, BIS and BAS could differentiate between GAD, SAD and PD using the Jackson-5 scale. The results may help us understand better the personality-related pathology underlying anxiety disorders.

\section{PARTICIPANTS AND PROCEDURE}

\section{PARTICIPANTS}

Participants included 226 out-patients; of these, 78 met the DSM-IV criteria for GAD, 76 for SAD and 72 for PD. Comorbidity was common, with $27.29 \%$ experiencing substance abuse, $24.70 \%$ depression, and $29.85 \%$ experiencing a secondary anxiety disorder. Further, 85 healthy controls were recruited and matched for age and education. The clinical cohort was recruited from four sites, the Kargarnejad Hospital, the Clinical Research Development Uni-Matini, the Special Clinic for Clinical Psychology Research, and the Psychiatric Institute of Mental Health in Kashan, Iran. The control group was recruited from healthy people of Kashan on the basis of the absence of current axis I disorders of DSM-IV and confirmed by psychiatric assessment. All GAD, SAD, and PD patients were on medication: the most commonly used medications in GAD patients were paroxetine (84\%), pregabalin $(81 \%)$, and fluoxetine $(77 \%)$; the most commonly used medications in SAD included benzodiazepine (100\%) and fluoxetine (76\%); and the most commonly used medications in PD were benzodiazepine (100\%) and antidepressants (68\%). The demographic and clinical characteristics of the groups are shown in Table 1.

\section{PROCEDURE}

Ethical approval for this study was obtained from the Research Deputy of Kashan University of Medical Sciences. Participants were given information about the study and provided informed consent in writing. Once consent was provided, participants completed demographic information and several questionnaires in Persian during an in-person visit. Further, participant medical records were made available to the researchers. Participant diagnoses and medication data were extracted from patient medical records. Patient inclusion criteria were the presence of GAD, SAD, and $\mathrm{PD}$, and an educational level higher than eighth grade - this was needed to ensure that the personality questionnaires were understood. The only exclusion criteria for the clinical groups were a current psychotic episode. The relaxed inclusion and exclusion criteria ensured that the clinical samples closely reflected the population presenting for treatment. Their r-RST scores were compared with 85 matched healthy controls selected on the basis of the absence of current axis I disorders of DSM-IV and confirmed by psychiatric assessment. Data were collected between July 2018 and May 2019.

\section{MEASURES}

Structured Clinical Interview for DSM-IV Axis I disorders (SCID-I). SCID-I has a screening form including 24 items evaluating symptomology for various axis I disorders (Afshari, Khezrian, \& Faghihi, 2019; First, Spitzer, Gibbon, \& Williams, 1995). Diagnostic agreement between test and retest SCID administration was fair to good for most diagnostic categories in Iranian society. Overall weighted $\kappa$ was 0.52 for current diagnoses and 0.55 for lifetime diagnoses. Specificity values for most psychiatric disorders were high 
Table 1

Demographic and clinical characteristics of participants

\begin{tabular}{|c|c|c|c|c|}
\hline Characteristics & $\begin{array}{c}\text { GAD } \\
(n=78)\end{array}$ & $\begin{array}{c}\text { SAD } \\
(n=76)\end{array}$ & $\begin{array}{c}\text { PD } \\
(n=72)\end{array}$ & $\begin{array}{c}\mathrm{HC} \\
(n=85)\end{array}$ \\
\hline Average age (years) & $28.20(3.02)$ & $31.10(5.00)$ & $29.50(2.04)$ & $28.40(4.02)$ \\
\hline Gender $(M / F)$ & $34 / 44$ & $41 / 35$ & $37 / 35$ & $41 / 44$ \\
\hline Years of education & $10.05(2.00)$ & $11.00(2.00)$ & $10.07(2.04)$ & $12.00(3.00)$ \\
\hline BDI-II & $14.05(5.00)$ & $9.01(2.01)$ & $16.04(2.04)$ & $7.02(2.00)$ \\
\hline First diagnostic age (years) & $23.00(3.06)$ & $21.07(4.00)$ & $22.07(2.02)$ & \\
\hline Number of hospitalizations & $0.43(1.04)$ & $0.07(2.09)$ & $1.02(2.01)$ & \\
\hline Comorbidity & $54.78 \%$ & $22.16 \%$ & $35.23 \%$ & \\
\hline Substance abuse & $34.25 \%$ & $18.23 \%$ & $29.41 \%$ & \\
\hline Depression & $42.33 \%$ & $14.41 \%$ & $17.36 \%$ & \\
\hline Other anxiety disorders & $45.69 \%$ & $12.74 \%$ & $31.13 \%$ & \\
\hline
\end{tabular}

( $>0.85$ ); the sensitivity values were lower (Sharifi et al., 2009).

fackson-5 Questionnaire. Jackson (2009) designed this 30 -item questionnaire to assess r-RST. The questionnaire consists of five subscales: Behavioral Activation System (BAS), Behavioral Inhibition System (BIS), Fight, Flight, and Freeze system - each scale includes 6 items. The response is on a 5-point Likert scale from 1 (always) to 5 (never). In an Iranian community Cronbach's $\alpha$ was reported to be: $\mathrm{r}$-BAS $=.81, \mathrm{r}$-BIS $=.88$, Fight $=.74$, Flight $=.72$, and Freeze $=.77$. The questionnaire demonstrates acceptable reliability in the current study for all five subscales (Cronbach's $\alpha .68$ to .87; Table 2) (Afshari, Rasouli-Azad, \& Ghoreishi, 2019; Hasani, Salehi, \& Rasouli-Azad, 2012).

Beck Depression Inventory (BDI-II). This 21-item self-report questionnaire is designed to assess depression syndrome; scores range from 0 to 63 (Beck, Steer, \& Brown, 1996). Studies on the concurrent validity of the BDI in American society report a moderate to high correlation coefficient with a mean from .58 to .79 (Richter, Werner, Heerlein, Kraus, \& Sauer, 1998). Internal stability in the Iranian community is moderate to good (Cronbach's $\alpha=.58$ ) and its reliability by test-retest is .73 (Meygoni \& Ahadi, 2012).

Generalized Anxiety Disorder Questionnaire (GAD-7). This scale was developed by Spitzer et al. (2006) and has 7 questions, each of which addresses the psychological problems experienced by the subject in the past two weeks. Scores on this scale range from 0 to 21. Also, Spitzer et al. (2006) reported the Cronbach's $\alpha$ coefficient and the retest coefficient of this scale as .92 and .83 , respectively. The correlation coefficient of the anxiety scale with the Beck Anxiety Inventory was .77 and .74 with the psychological check list of
90 questions. The results of this study showed that Cronbach's $\alpha$ coefficient was .85 , indicating the reliability of this scale (Spitzer, Kroenke, Williams, \& Löwe, 2006).

Social Phobia Inventory (SPIN). The SPIN questionnaire measures social phobia. It is a self-assessment scale of 17 questions, which has three levels of avoidance, fear and physiological discomfort. Each item is graded on a Likert scale (from 0 to 5). In an Iranian society, Cronbach's $\alpha$ for the first half of the measure was .82 , the second half of the measure was .76, and ultimately, the correlation of these two was .84 . Cronbach's $\alpha$ for avoidance, fear and physiological discomfort subscales respectively were $.75, .74$, and .75 (Tashkeh \& Bazani, 2015).

Panic and Agoraphobia Scale (P \& A). The P \& A contains 13 items to which participants respond on a 0-4 point Likert scale. It includes five subscales: (1) Panic Attacks, (2) Agoraphobia, (3) Anticipatory Anxiety, (4) Disability, and (5) Worries about Health. The total score is obtained by summing the item scores. Data showed satisfactory values for internal consistency (Cronbach's $\alpha$ ), test-retest reliability, inter-rater reliability, internal validity and correlation with other anxiety scales. The external validity of the scale was shown to be better than in other previously used scales (Bandelow et al., 2000).

\section{DATA ANALYSES}

SPSS 21 was used to determine basic statistics for all variables of interest and to perform the chi-squared analyses, Kolmogorov-Smirnov, MANCOVA, and the independent $t$-tests to compare demographic and 
clinical variables in four groups. Chi-squared analyses and a MANCOVA were used to evaluate group equivalency at baseline.

\section{RESULTS}

\section{DESCRIPTIVE STATISTICS}

In the GAD and $\mathrm{HC}$ groups, there were more women than men; in the SAD and PD groups, there were more men than women, but this difference was not statistically significant. The mean age of the SAD group, and level of education of the HC group, were higher than in the other three groups. The age of the first diagnosis was lower in the SAD group. The mean number of hospitalizations of the PD group and co-morbidity with other disorders in the GAD group were higher than in the other three groups. The rate of depression in the PD group $(M=16.04$, $S D=2.04)$ was higher than in the other groups.

\section{R-RST RESULTS}

The results of MANCOVA showed a significant difference between group differences on Jackson-5 scales $(F=22.6, p=.001)$. The results of the post hoc Games-Howell test showed that this difference lies between the PD patients and the other three groups. In other words, patients with PD had lower r-BAS and r-BIS scores than those with GAD, SAD, and the HC group (Table 2 and Figure 1). The attachment differences between groups were statistically signifi- cant, controlling for depression (MANCOVA: $F=72.5$, $p=.001)$ in all five subscales.

The scores of the PD group in r-BAS, r-BIS, and Freeze were lower than those in the other three groups, but in Fight and Flight, the scores of the PD group were higher than those in the other three groups. Also, GAD, SAD, and PD groups were higher on Flight than the control group, and there was no difference between GAD and SAD groups on this scale. For the Fight scale, the scores of the control group were lower than those of the SAD and PD groups, but higher than those of the GAD group. The effect size of the groups for Flight and Freeze was lower than the other scales, and the greatest effect size was for r-BAS.

\section{DISCUSSION}

This is the first study to examine r-RST in generalized anxiety disorder (GAD), social anxiety disorder (SAD), and panic disorder (PD) patients. According to r-RST findings, GAD patients had higher scores than the other groups on the r-BIS scale. This finding is in line with previous studies (Yen, Ko, Yen, Chen, \& Chen, 2009). Behavior inhibition represents sensitivity to aversive stimuli. Also, behavior inhibition can prohibit patients from trying activities and interaction in social interactions. It makes them prone to desire to escape from relationships (Wang et al., 2017). There are some psychometric issues to consider. Walker, Jackson, and Frost (2017) explained that the BIS scale from the Jackson-5 measures a form of social comparison, which narrows down the content

Table 2

Results of the multivariate analysis of variance (MANOVA) in r-RST subscales

\begin{tabular}{|c|c|c|c|c|c|c|c|c|c|c|c|}
\hline \multirow[t]{2}{*}{ Variable } & \multicolumn{2}{|c|}{$\begin{array}{l}\text { GAD } \\
n=78\end{array}$} & \multicolumn{2}{|c|}{$\begin{array}{c}\text { SAD } \\
n=76\end{array}$} & \multicolumn{2}{|c|}{$\begin{array}{c}\text { PD } \\
n=72\end{array}$} & \multicolumn{2}{|c|}{$\begin{array}{c}\mathrm{HC} \\
n=85\end{array}$} & \multirow[t]{2}{*}{$p$} & \multirow[t]{2}{*}{$\eta^{2}$} & \multirow[t]{2}{*}{$\begin{array}{l}\text { Games- } \\
\text { Howell }\end{array}$} \\
\hline & $M$ & $S D$ & $M$ & $S D$ & $M$ & $S D$ & $M$ & $S D$ & & & \\
\hline r-BAS & 21.84 & 4.07 & 20.24 & 4.08 & 18.36 & 2.02 & 21.32 & 4.12 & .001 & 0.36 & $\begin{array}{c}\mathrm{GAD}>\mathrm{HC} \\
>\mathrm{SAD}>\mathrm{PD}^{* * *}\end{array}$ \\
\hline$r-B I S$ & 22.97 & 3.03 & 22.13 & 3.04 & 18.68 & 1.14 & 22.54 & 3.14 & .001 & 0.25 & $\begin{array}{c}\mathrm{GAD}>\mathrm{SAD} \\
>\mathrm{PD}^{*} \\
\mathrm{SAD}=\mathrm{HC}^{* *}\end{array}$ \\
\hline Fight & 16.22 & 3.03 & 18.58 & 4.07 & 24.65 & 2.07 & 18.16 & 2.06 & .002 & 0.23 & $\begin{aligned} \mathrm{PD} & >\mathrm{SAD} \\
>\mathrm{HC} & >\mathrm{GAD}^{* *}\end{aligned}$ \\
\hline Flight & 19.16 & 3.05 & 19.32 & 3.17 & 23.82 & 3.11 & 13.34 & 3.04 & .001 & 0.04 & $\begin{array}{c}\mathrm{PD}>\mathrm{GAD} \\
\& \mathrm{SAD}>\mathrm{HC} \\
\mathrm{GAD}=\mathrm{SAD}^{* *}\end{array}$ \\
\hline Freeze & 17.42 & 3.12 & 15.86 & 2.09 & 13.31 & 1.18 & 15.07 & 2.12 & .001 & 0.07 & $\begin{array}{c}\mathrm{GAD}>\mathrm{SAD} \\
>\mathrm{HC}>\mathrm{PD}^{* * *}\end{array}$ \\
\hline
\end{tabular}

Note. ${ }^{*}$ tend to significance, ${ }^{* *} p<.05,{ }^{* * *} p<.01$. 

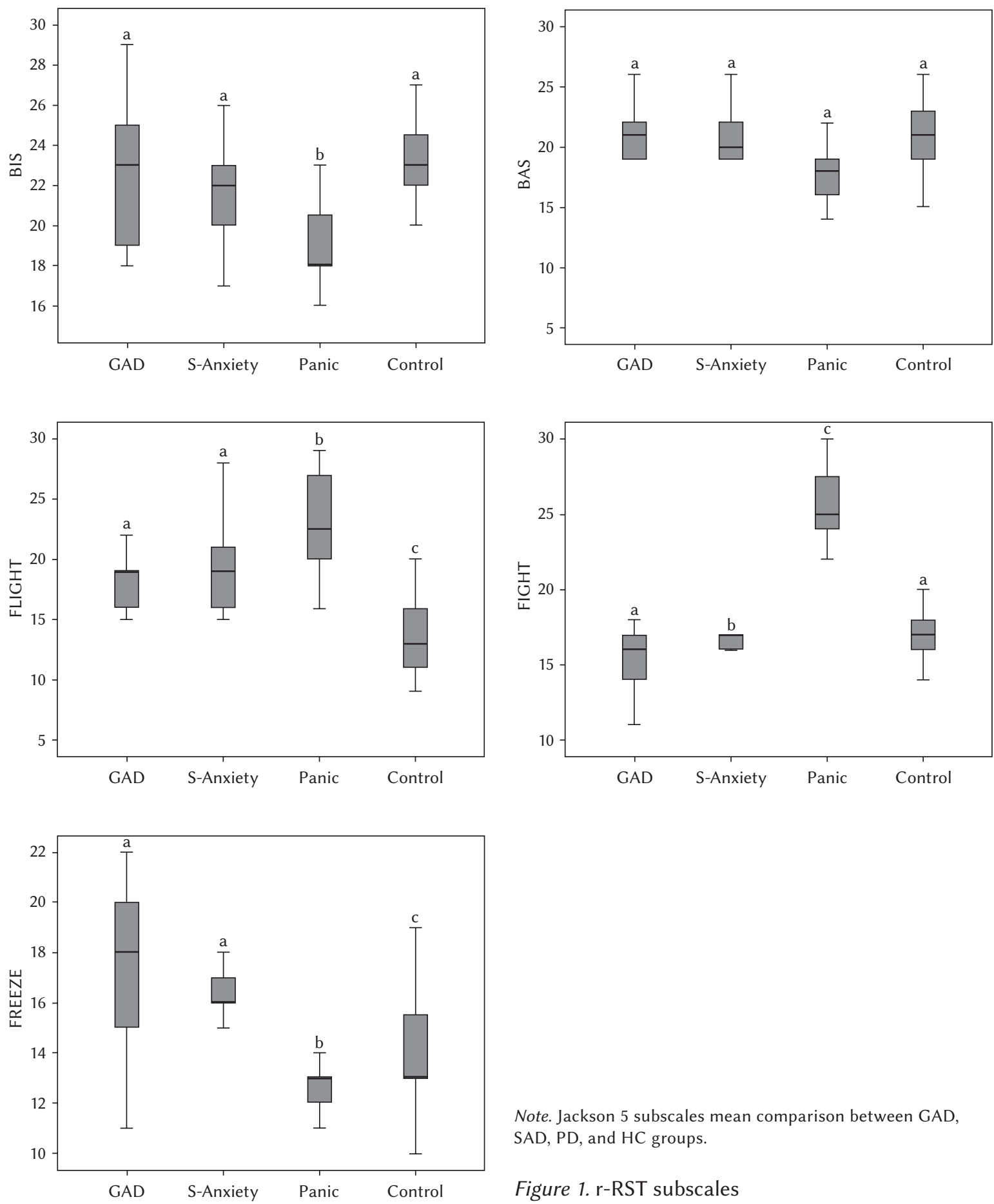

Note. Jackson 5 subscales mean comparison between GAD, $\mathrm{SAD}, \mathrm{PD}$, and $\mathrm{HC}$ groups.

Figure 1. r-RST subscales

of the BIS. The finding in the present study likely is related to construct validity of r-BIS in Jackson-5; GAD patients are more prone to social comparison due to their symptoms (APA, 2000).

In the r-BAS scale, the score of the PD group was lower than that of the other groups; and other groups were equal on this scale. BAS is thought to produce positive feelings in response to signals of reward and to provoke movement toward desired goals. Also, BAS low activity is related to disorders that involve low mood, withdrawal, and decreased pursuit of goals (Jorm et al., 1998). This finding is related to patients with anxiety disorders due to their symptoms (APA, 2000).

In the Fight scale, the score of the PD group was higher than that of the other groups; the score of the SAD group was lower than that of the PD group but higher than that of the GAD and HC groups; and the score of the GAD group was lower than that of the SAD and PD groups but equal to that of the HC 
group. Defensive fight is an alternative adaptive reaction against danger, which occurs when flight is impossible, but this strategy relates to rage rather than PD (Graeff, 2007). In the Flight scale, the score of the PD group was higher than that of the other groups; the scores of GAD and SAD were equal, and both groups were lower than the PD group but higher than the HC group. PD is responsible for a vigorous flight reaction evoked by very close danger like proximal danger (Graeff, 2007). Another view is that PD manifests itself primarily as flight behavior (Quarantelli, 2001). In the Freeze scale, the score of the PD group was lower than that of the other groups; the score of the GAD group was higher than that of the other groups; the score of the SAD group was lower than that of GAD but higher than that of PD and HC groups. The freezing behavior occurs in the cases in which the actual threat stimuli are unavoidable while the avoidable ones induce anger-related fight or fear-related flight (Corr, 2008). Increased freezing in GAD in the present study is in line with previous studies showing high prevalence of depression in this disorder (APA, 2000). FFFS in r-RST is found in association with anxiety, depression, restrictive anorexia nervosa, schizophrenia and cluster $\mathrm{C}$ personality disorders as well as o-BIS (Bijttebier, Beck, Claes, \& Vandereycken, 2009).

The results of the present study should be of significant value for future research which has the aim of: (1) examining r-RST in mental health; (2) understanding the role of personality vulnerabilities in mental health; (3) using reliable and credible tools to assess r-RST in psychopathological research. It is likely that such research will throw new light onto the etiology and development of continuation of common mental disorders.

Finally, our results have some implications. In diagnosis, Jackson 5 scales can be implemented to differentiate anxiety disorders. In psychotherapy, behavioral inhibition treatment is suitable for improving mental disorders as a recent pilot study has shown (Campbell-Sills, Liverant, \& Brown, 2004; Foa, Riggs, Massie, \& Yarczower, 1995; Wilhelm et al., 2005). It inhibits behaviors that increase contact with environmental contingency reinforcements. Indeed, emotion regulation focused psychotherapies (e.g. DBT) possibly are more appropriate for anxiety disorders that had higher r-BAS and r-BIS sensitivity. All patients were under medication and this may have affected their personality scores. We suggest that future researchers should try to obtain GAD/SAD/PD patient samples not on medication. Another limitation concerns the use of Jackson- 5 questionnaires. We suggest using other tools (e.g. RST-PQ; Corr \& Cooper, 2016) to examine RST. Krupic and Corr (2017) classified the BAS scales of several RST questionnaires into four distinct categories, whereas Jackson-5 has only one scale for BAS (Krupić \& Corr, 2017).

\section{REFERENCES}

Afshari, B., Khezrian, K., \& Faghihi, A. (2019). Examination and comparison of cognitive and executive functions in patients with schizophrenia and bipolar disorders. Journal of Isfahan Medical School, 37, 270-277. https://doi.org/10.22122/jims. v37i320.11149

Afshari, B., Rasouli-Azad, M., \& Ghoreishi, F. S. (2019). Comparison of original and revised reinforcement sensitivity theory in clinically-stable schizophrenia and bipolar disorder patients. Personality and Individual Differences, 138, 321-327. https://doi.org/ 10.1016/j.paid.2018.10.026

APA (2000). Diagnostic and statistical manual of mental disorders (DSM-IV-TR). Washington, DC: APA Publishing.

APA (2013). Diagnostic and statistical manual of mental disorders (DSM-5). Washington, DC: APA Publishing.

Bandelow, B., Broocks, A., Pekrun, G., George, A., Meyer, T., Pralle, L., Bartmann, U., Hillmer-Vogel, U., \& Rüther, E. (2000). The use of the Panic and Agoraphobia Scale ( $P$ \& A) in a controlled clinical trial. Pharmacopsychiatry, 33, 174-181. https://doi. org/10.1055/s-2000-12982

Beck, A. T., Steer, R. A., \& Brown, G. K. (1996). Manual for the Beck Depression Inventory-II. San Antonio, TX: Psychological Corporation.

Bienvenu, O. J., Hettema, J. M., Neale, M. C., Prescott, C. A., \& Kendler, K. S. (2007). Low extraversion and high neuroticism as indices of genetic and environmental risk for social phobia, agoraphobia, and animal phobia. American Journal of Psychiatry, 164, 1714-1721. https://doi.org/10.1176/ appi.ajp.2007.06101667

Bijttebier, P., Beck, I., Claes, L., \& Vandereycken, W. (2009). Gray's reinforcement sensitivity theory as a framework for research on personality-psychopathology associations. Clinical Psychology Review, 29, 421-430. https://doi.org/10.1016/j.cpr.2009. 04.002

Campbell-Sills, L., Liverant, G. I., \& Brown, T. A. (2004). Psychometric evaluation of the behavioral inhibition/behavioral activation scales in a large sample of outpatients with anxiety and mood disorders. Psychological Assessment, 16, 244-254. https://doi.org/10.1037/1040-3590.16.3.244

Carrera, M., Herran, A., Ramirez, M., Ayestarán, A., Sierra-Biddle, D., Hoyuela, F., Rodríguez-Cabo, B., \& Vázquez-Barquero, J. L. (2006). Personality traits in early phases of panic disorder: Implications on the presence of agoraphobia, clinical severity and short-term outcome. Acta Psychiatrica Scandinavica, 114, 417-425. https://doi.org/10.1111/j.16000447.2006.00826.x

Claridge, G., \& Davis, C. (2013). Personality and psychological disorders. New York: Routledge. 
Cloninger, C. R., Zohar, A. H., Hirschmann, S., \& Dahan, D. (2012). The psychological costs and benefits of being highly persistent: personality profiles distinguish mood disorders from anxiety disorders. Journal of Affective Disorders, 136, 758-766. https://doi.org/10.1016/j.jad.2011.09.046

Corr, P. J. (2008). Reinforcement sensitivity theory (RST): Introduction. In P. J. Corr (Ed.), The reinforcement sensitivity theory of personality (pp. 1-43). Cambridge: Cambridge University Press

Corr, P. J., \& Cooper, A. J. (2016). The Reinforcement Sensitivity Theory of Personality Questionnaire (RST-PQ): Development and validation. Psychological Assessment, 28, 1427-1440. https://doi.org/ $10.1037 /$ pas0000273

Cremers, H. R., \& Roelofs, K. (2016). Social anxiety disorder: a critical overview of neurocognitive research. Wiley Interdisciplinary Reviews. Cognitive Science, 7, 218-232. https://doi.org/10.1002/ wcs. 1390

First, M. B., Spitzer, R. L., Gibbon, M., \& Williams, J. B. (1995). The structured clinical interview for DSMIII-R personality disorders (SCID-II). Part I: Description. Journal of Personality Disorders, 9, 83-91. https://doi.org/10.1521/pedi.1995.9.2.83

Flett, G. L., Hewitt, P. L., \& Dyck, D. G. (1989). Selforiented perfectionism, neuroticism and anxiety. Personality and Individual Differences, 10, 731-735. https://doi.org/10.1016/0191-8869(89)90119-0

Foa, E. B., Riggs, D. S., Massie, E. D., \& Yarczower, M. (1995). The impact of fear activation and anger on the efficacy of exposure treatment for posttraumatic stress disorder. Behavior Therapy, 26, 487499. https://doi.org/10.1016/S0005-7894(05)80096-6

Graeff, F. G. (2007). Anxiety, panic and the hypothalamic-pituitary-adrenal axis. Revista Brasileira de Psiquiatria, 29, s3-s6. https://doi.org/10.1590/S151644462007000500002

Gray, J. A. (1981). A critique of Eysenck's theory of personality. In H. J. Eysenck (Ed.), A model for personality (pp. 246-276). Berlin, Heidelberg: Springer.

Gray, J. A. (1982). Oxford psychology series. The neuropsychology of anxiety: an enquiry into the functions of the septo-hippocampal system. New York: Clarendon Press/Oxford University Press.

Gray, J. A. (1987). Problems in the behavioural sciences, Vol. 5. The psychology of fear and stress (2nd ed.). Cambridge: Cambridge University Press.

Gray, J. A., \& McNaughton, N. (2000). The neuropsychology of anxiety. New York: Oxford University Press.

Harnett, P. H., Loxton, N. J., \& Jackson, C. J. (2013). Revised reinforcement sensitivity theory: Implications for psychopathology and psychological health. Personality and Individual Differences, 54, 432-437. https://doi.org/10.1016/j.paid.2012.10.019

Hasani, J., Salehi, S., \& Rasouli-Azad, M. (2012). Psychometric properties of Jackson's Five Factor
Questionnaire: Scales of revised reinforcement sensitivity theory (r-RST). Research in Psychological Health, 6, 60-73.

Jackson, C. J. (2009). Jackson-5 scales of revised reinforcement sensitivity theory ( $r-\mathrm{RST})$ and their application to dysfunctional real world outcomes. Journal of Research in Personality, 43, 556-569. https://doi.org/10.1016/j.jrp.2009.02.007

Jorm, A. F., Christensen, H., Henderson, A. S., Jacomb, P. A., Korten, A. E., \& Rodgers, B. (1998). Using the BIS/BAS scales to measure behavioural inhibition and behavioural activation: Factor structure, validity and norms in a large community sample. Personality and Individual Differences, 26, 49-58. https://doi.org/10.1016/S0191-8869(98)00143-3

Kashdan, T. B. (2002). Social anxiety dimensions, neuroticism, and the contours of positive psychological functioning. Cognitive Therapy and Research, 26, 789-810. https://doi.org/10.1023/A:1021293501345

Kessler, R. C., Gruber, M., Hettema, J. M., Hwang, I., Sampson, N., \& Yonkers, K. A. (2008). Co-morbid major depression and generalized anxiety disorders in the National Comorbidity Survey followup. Psychological Medicine, 38, 365-374. https:// doi.org/10.1017/S0033291707002012

Kotov, R., Watson, D., Robles, J. P., \& Schmidt, N. B. (2007). Personality traits and anxiety symptoms: The multilevel trait predictor model. Behaviour Research and Therapy, 45, 1485-1503. https://doi. org/10.1016/j.brat.2006.11.011

Krupić, D., \& Corr, P. J. (2017). Moving forward with the BAS: Towards a neurobiology of multidimensional model of approach motivation. Psychological Topics, 26, 25-45.

Lesser, I. M., Rubin, R. T., Pecknold, J. C., Rifkin, A., Swinson, R. P., Lydiard, R. B., Burrows, G. D., Noyes, R., \& DuPont, R. L. (1988). Secondary depression in panic disorder and agoraphobia: I. Frequency, severity, and response to treatment. Archives of General Psychiatry, 45, 437-443. https://doi.org/10.1001/ archpsyc. 1988.01800290053007

McNaughton, N., \& Corr, P. J. (2008). The neuropsychology of fear and anxiety: a foundation for reinforcement sensitivity theory. In P. J. Corr (Ed.), The reinforcement sensitivity theory of personality ( $\mathrm{pp}$. 44-94). Cambridge: Cambridge University Press.

Meygoni, A. K. M., \& Ahadi, H. (2012). Declining the rate of major depression: Effectiveness of dialectical behavior therapy. Procedia - Social and Behavioral Sciences, 35, 230-236. https://doi. org/10.1016/j.sbspro.2012.02.083

Moffitt, T. E., Harrington, H., Caspi, A., Kim-Cohen, J., Goldberg, D., Gregory, A. M., \& Poulton, R. J. (2007). Depression and generalized anxiety disorder: Cumulative and sequential comorbidity in a birth cohort followed prospectively to age 32 years. Archives of General Psychiatry, 64, 651-660. https://doi.org/10.1001/archpsyc.64.6.651 
Neal, L. B., \& Gable, P. A. (2017). Regulatory control and impulsivity relate to resting frontal activity. Social Cognitive and Affective Neuroscience, 12, 1377-1383. https://doi.org/10.1093/scan/nsx080

Nolen-Hoeksema, S. (2000). The role of rumination in depressive disorders and mixed anxiety/depressive symptoms. Journal of Abnormal Psychology, 109, 504511. https://doi.org/10.1037/0021-843X.109.3.504.

Ohayon, M. M., \& Schatzberg, A. F. (2010). Social phobia and depression: Prevalence and comorbidity. Journal of Psychosomatic Research, 68, 235-243. https://doi.org/10.1016/j.jpsychores.2009.07.018

Quarantelli, E. L. (2001). The sociology of panic. Disaster Research Center, University of Delaware, Newark.

Richter, P., Werner, J., Heerlein, A., Kraus, A., \& Sauer, H. (1998). On the validity of the Beck Depression Inventory. Psychopathology, 31, 160-168. https://doi.org/10.1159/000066239

Sharifi, V., Assadi, S. M., Mohammadi, M. R., Amini, H., Kaviani, H., Semnani, Y., Shabani, A., Shahrivar, Z., Davari-Ashtiani, R., Shooshtari, M. H., Seddigh, A., \& Jalali, M. (2009). A Persian translation of the structured clinical interview for „Diagnostic and statistical manual of mental disorders": psychometric properties. Comprehensive Psychiatry, 50, 86-91. https://doi.org/10.1016/j.comppsych.2008.04.004

Sharma, S. C. (2003). Generalized anxiety disorder and personality traits. Kathmandu University Medical Journal, 1, 248-250.

Solmaz, M., Kulacaoglu, F., Sagir, S., Ardic, F. C., Balcioglu, Y. H., \& Kose, S. (2018). Temperament and character dimensions of personality in social anxiety disorder with and without comorbid major depressive disorder. Klinik Psikofarmakoloji Bulteni, 28, 95-96.

Spitzer, R. L., Kroenke, K., Williams, J. B., \& Löwe, B. (2006). A brief measure for assessing generalized anxiety disorder: the GAD-7. Archives of Internal Medicine, 166, 1092-1097. https://doi.org/10.1001/ archinte.166.10.1092

Starcevic, V., Uhlenhuth, E., Fallon, S., \& Pathak, D. (1996). Personality dimensions in panic disorder and generalized anxiety disorder. Journal of Affective Disorders, 37, 75-79. https://doi.org/10.1016/01650327(95)00058-5

Stein, M. B., \& Chavira, D. A. (1998). Subtypes of social phobia and comorbidity with depression and other anxiety disorders. Journal of Affective Disorders, 50, S11-S16. https://doi.org/10.1016/S01650327(98)00092-5

Stein, M. B., \& Stein, D. J. (2008). Social anxiety disorder. The Lancet, 371, 1115-1125. https://doi. org/10.1016/S0140-6736(08)60488-2

Tashkeh, M., \& Bazani, M. (2015). Prediction of social anxiety by cognitive emotional regulation and emotional schema in female and male students. Zanko Journal of Medical Sciences, 16, 72-83.
Walker, B. R., Jackson, C. J., \& Frost, R. (2017). A comparison of revised reinforcement sensitivity theory with other contemporary personality models. Personality and Individual Differences, 109, 232236. https://doi.org/10.1016/j.paid.2016.12.053

Wang, C. Y., Wu, Y. C., Su, C. H., Lin, P. C., Ko, C. H., \& Yen, J. Y. (2017). Association between Internet gaming disorder and generalized anxiety disorder. Journal of Behavioral Addictions, 6, 564-571. https://doi.org/10.1556/2006.6.2017.088

Wilhelm, F. H., Pfaltz, M. C., Gross, J. J., Mauss, I. B., Kim, S. I., \& Wiederhold, B. K. (2005). Mechanisms of virtual reality exposure therapy: The role of the behavioral activation and behavioral inhibition systems. Applied Psychophysiology and Biofeedback, 30, 271-284. https://doi.org/10.1007/s10484005-6383-1

Yen, J.Y., Ko, C. H., Yen, C. F., Chen, C. S., \& Chen, C. C. (2009). The association between harmful alcohol use and internet addiction among college students: Comparison of personality. Psychiatry and Clinical Neurosciences, 63, 218-224. https://doi. org/10.1111/j.1440-1819.2009.01943.x 